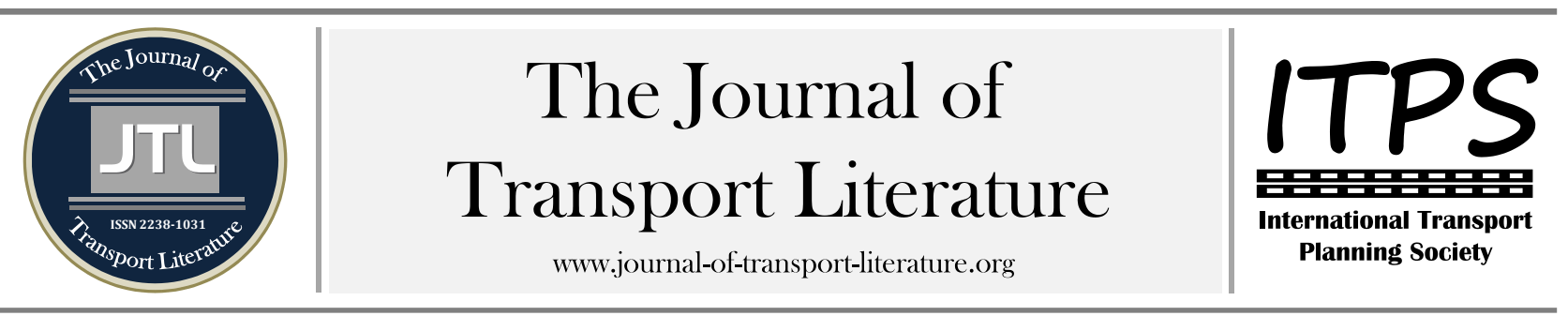

\title{
Assessment of the services on road transportation of dangerous goods
}

\author{
Marne Lieggio Júnior ${ }^{1,+}$; Sérgio Ronaldo Granemann¹; Carlos Henrique Rocha1; Orlando Fontes Lima Júnior ${ }^{2}$ \\ ${ }^{1}$ Universidade de Brasília, Brasília, Brasil \\ 2 Unicamp, Campinas, Brasil
}

\section{Article Info}

Keywords: road transportation of dangerous goods; accident risks; multi-criteria decision support;

performance classification; Electre Tri.

Submitted 6 Oct 2014 received in revised form 22 May 2015; accepted 12 Jul 2015.

Licensed under

Creative Commons

CC-BY 3.0 BR.

\section{Abstract}

The goal of this paper is to propose a methodology to assess the services provided by companies that work with road transportation of dangerous goods. The scientific contribution is to fill the existing void in the literature by means of a methodology that brings together: the identification and analysis of the key stakeholders; multicriterial decision support; multivariate data analysis; and classification of the performance profiles of services. The proposed methodology is divided into the following steps: identifying and analyzing the main stakeholders; identifying the main desired requirements of a company that works with road transportation of dangerous goods; obtaining the weights of the desired requirements and of the aspects considered; and classifying the services provided by these companies. A hypothetical example allowed: identified the main actors; list the key attributes desirable in categories; get their weights; enumerate the alternatives for services rendered; define the Accident Risk Classes; and classify the services provided to contracting in optimistic and pessimistic scenarios.

+ Corresponding author. Universidade de Brasília - UnB, Brasília, DF, 70910-900, Brasil.

E-mail address: marnejr@gmail.com.

\section{Introduction}

The objective of this paper is to realize a methodological proposal to identify and assess desired requirements that companies working with road transportation of dangerous goods (RTDG) should meet, so that the government can assess and classify the services they provide concerning accident risks, taking into account the joint view of the main groups of actors. In the face of the legal framework and the risks intrinsic to the transportation of this kind of load, the liability of those who own the load and those who transport it, who might suffer from financial to freedom-restricting sanctions, becomes evident. Thus there have been initiatives both from the owners' and from the shippers' side aimed at establishing programs to assess the services provided by RTDG companies in order to guarantee that they have been meeting mandatory and non-mandatory requirements. This means that the transportation segment itself demands such companies to meet legal requirements, as well as certain desired requirements (certificates concerning Risk Management, Environment and Occupational Safety and Health, for instance), which shows an innovation in the logistic chain of transportation of this kind of load.

Even in developed countries in North America and Europe there is no compulsory program established by the government to assess and classify the services provided by companies that work with road transportation of dangerous goods. However, there are some examples of compliance assessment programs: (i) regarding load owners, there is the System of Assessment of Safety, Health, Environment and Quality (Sassmaq, in Portuguese), an initiative of the Brazilian Chemical Industry Association (Abiquim); and (ii) regarding shippers, there is Transqualit Green, an initiative of the National Association of Load Transportation and Logistics (NTC, in Portuguese) in Brazil. With respect to literature contribution, this paper fills the gap found, using important tools such as the Preliminary Regulatory Impact Analysis, identification and analysis of stakeholders' strengths, Factor Analysis, and Multi-Criteria Decision Support for classification problems (Electre Tri).

Some methodologies assess the risk of accidents in RTDG, involving a route selection, scheduling, transport network or a combination of these elements (Fisichella et al., 2009; Russo et al., 2008). However, the process to come closer to the market and institutional needs is the one that provides for the establishment by the government of a mechanism to assess and classify the services provided by companies working with the transport of dangerous goods in respect of the accident risk having regard to the joint vision of all key stakeholders in relation to the issue as well as identifying the key desired requirements that a specialized company must comply (LIEGGIO JÚNIOR, 2008; 2012). The application of the methodology for a theoretical case allowed the main actors related to the issue were identified; listed the key attributes desirable in categories; obtained their weights; listed the alternatives of services rendered; defined casualty risk classes; and classified the services provided to contracting in optimistic and pessimistic scenarios.

The present article is divided into five items, including this introduction. Item 2 presents a definition of dangerous goods for what concerns transportation and a view of accidents. Item 3 discusses assessment and classification of the services 
provided by companies working with road transportation of dangerous goods regarding accident risks. Item 4 concerns the proposed methodology, with a hypothetical example. Finally, the conclusions are presented.

\section{Road transportation of dangerous goods}

A dangerous good can be defined as every substance or article found in nature or produced by any process which, due to its physical-chemical characteristics, represents a risk to people's health, to public safety or to the environment (ANTT, 2015; UNECE, 2013).

Figure 1 shows the chart representing the number of fatalities resulting from accidents in the transportation of dangerous goods in the USA, by means of transportation, in the period between Jan/1997 and Jun/2012. From 2004 to 2005 , according to the data collected, there was an $84.65 \%$ increase in the number of fatalities. From 2006 to 2007 , there was a $66.67 \%$ increase. However, from 2007 to 2011, there was a fluctuation inside a virtually constant range. Taking into consideration the last fifteen years, road transportation is the top means of transportation regarding fatalities, with $88.44 \%$ of the cases with fatal victims. This shows the need to assess and classify the services provided by companies working with road transportation of dangerous goods regarding accident risks.

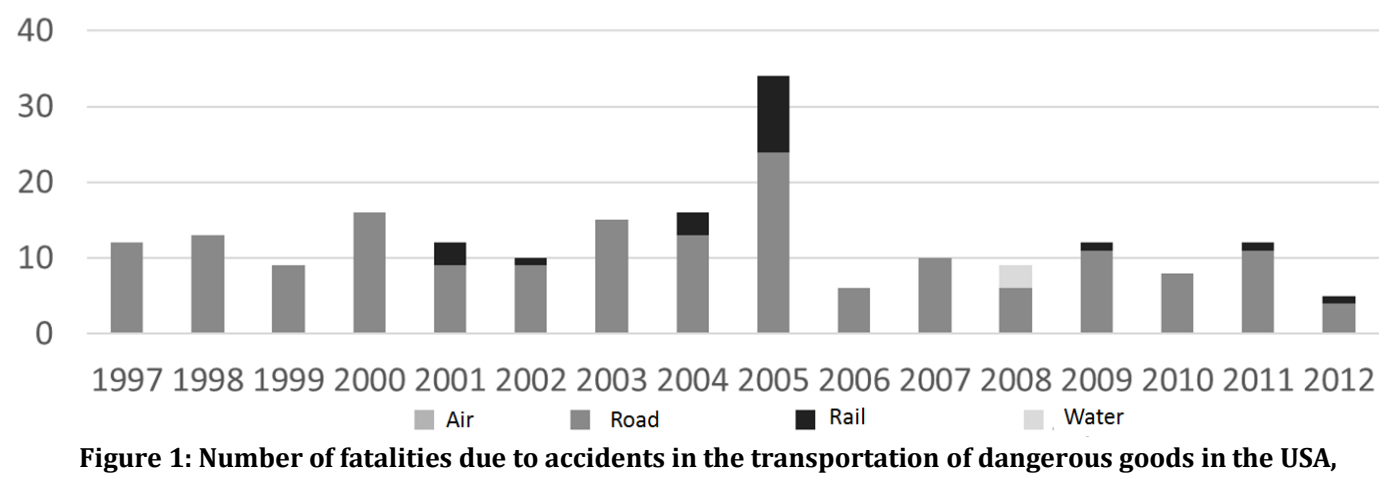

by means of transportation, in the period between January/1997 and June/2012. Source: PHMSA (2015).

\section{Assessing the services provided by RTDG companies}

Among the various methodologies concerning the assessment of accident risks in the road transportation of dangerous goods, those related to route selection, schedule, transportation network project and combined facilities become prominent. They use qualitative and/or quantitative analyses, specific software for analyzing and assessing accident risks, simulators for accidents with dangerous goods and Geographic Information Systems (GIS) (FISICHELLA et al., 2009; Russo et al., 2008).

However, the process that would come closer to the market and institutional needs is the one which foresees the establishment, by the government, of a mechanism for assessing and classifying the services provided by RTDG companies regarding accident risks, taking into account the joint view of all the main actors related to the issue, as well as the identification of the main desired requirements that a specialized company must meet (LIEGGIO JÚNIOR, 2008; 2012).

\section{Proposed methodology}

In this line of reasoning, the proposed methodology involves the identification and analysis of the key stakeholders; multicriterial decision support; multivariate data analysis; and classification of the performance profiles of services. It is divided into the following steps: identifying and analyzing the main actors; identifying the main desired requirements of a company that works with road transportation of dangerous goods; obtaining the weights of the desired requirements and of the aspects considered; and classifying the services provided by these companies.

\subsection{Stage 1 - Identifying and analyzing of the most relevant actors}

To perform the identification and analysis of the most relevant actors in the road transport of dangerous goods (RTDG), is necessary an adaptation of the methodology proposed by Meyers (2005), considering the practical application to the issue and the possibility of division of tasks in sub-steps.

\subsubsection{Stage 1.1 - Identifying the most relevant actors}

According to Meyers (2005), to identify the most relevant actors, the following approaches may be used: (a) identification of important entities by staff and other individuals with knowledge of the system; (b) identification through records and industry data; and (c) identification and verification by other participants.

\subsubsection{Stage 1.2 -Investigation of interests of the most relevant actors and their characteristics}

Once the most relevant actor is identified, interests and characteristics are carefully checked. The following strategies are proposed by Meyers (2005): (a) free discussions to generate ideas and themes within a group of participants; (b) semistructured surveys with an informal list of subjects is used as a guide with a group of participants, leading other subjects come up and discussed; (c) demand for the existing RTDG data; (d) timelines for the history of the connections among policies, institutions and processes and their specific impacts, with discussion of the cause and effect of various changes in the RTDG industry; and (e) diagrams that help to devise a quick view of what is being planned or what is spoken, encouraging discussion. Through these strategies, as well as through direct observation and dialogue, the range of influences on the actors involved has to be observed. These influences include: (a) institutional organizational factors: mandates, rules, norms, strengths and weaknesses, dynamics, interactions and institutional culture; and (b) factors of individual motivation: ideological predispositions, pursuit of political objectives, position and control of resources, knowledge and personal experience; promoting own career; institutional loyalty, improves the status of its own entity, and attributes and personal goals. 


\subsection{Stage 2 - Identification of the main requirements desirable}

At this stage, the main desirable requirements of companies working with road transportation of dangerous goods are raised. However, are used: (a) primary data: obtained through the responses of actors to structured questionnaires; and (b) secondary data: obtained through research literature and documents.

\subsection{Stage 3 - Obtaining the weights of desired requirements}

This is the stage of obtaining the weights of the desirable requirements of a RTDG company identified in Stage 2, wherein a semi-structured questionnaire is used. To obtain the weights, Multivariate Analyses of Data is used, more specifically the statistical technique called factor Analysis - AF. Its use is not justified as a traditional tool for obtaining weights, but also to study the inter-relation considering different decisions, bringing enrichment of study (Tatham et al., 2009). Thus, the following sub-steps, they discuss how the AF is applied. And for the statistical calculations, is used SPSS software, widely used in similar studies (CORRAR et al., 2009). According to Tatham et al. (2009) e Corrar et al. (2009), the most common method is the Principal Component Analysis - ACP by which one seeks a linear combination between the variables, so that the maximum variance is explained by this combination. This procedure results orthogonal factors, in other words, uncorrelated and in ACP, it takes into account the total variance. According to the same authors, the most appropriate method is the R-mode factor analysis, which is the most common structure of a Factor Analysis. R-mode factor analysis is used in this stage, as the researcher seeks not only to identify underlying structures capable of being perceived not only by building relationships between variables and also the factor loadings compose the main factor, and its weight are used.

\subsection{Stage 4 - Classifying the services provided by companies}

According to Roy (1985), Yu (1992) and Mousseau \& Slowinski (1996), for the cases that involve the $\beta$ problematic, i.e. classification problems, the use of the Electre Tri method is recommended, even in the transportation industry (Lieggio Júnior, Granemann \& Souza, 2012).

\subsubsection{Stage 4.1 - Identifying the performance (alternatives) of the services provided by companies}

Once the main desired requirements for a RTDG company have been defined in Stage 2, one then proceeds to verify in the market of road transportation of dangerous goods the performance profiles for such companies. This is done through direct consultations with the organizations or institutions that represent the transportation industry (unions and trade associations). As a hypothetical example, assume that companies working with road transportation of dangerous goods have their services assessed in light of five groups of desired requirements (RD1 to RD5), each one containing five elements (RD1.1 to RD1.5 for the RD1 group, for instance) and the weights obtained according to Stage 4. Table 1 shows this example. Table 1: Hypothetical example of the desired requirements and respective weights.

\begin{tabular}{lll}
\hline $\begin{array}{l}\text { Groups of the } \\
\text { desired } \\
\text { requirements }\end{array}$ & Weight & Elements (aspects) considered \\
\hline RD1 & 0,25 & RD1.1 a RD1.5 \\
RD2 & 0,25 & RD2.1 a RD2.5 \\
RD3 & 0,20 & RD3.1 a RD3.5 \\
RD4 & 0,10 & RD4.1 a RD4.5 \\
RD5 & 0,20 & RD5.1 a RD5.5 \\
\hline
\end{tabular}

After the survey with the RTDG companies, it is possible to design a table with the profiles of the companies that have been consulted. Table 2 presents groups of requirements and desired aspects considered, which were obtained with 10 hypothetical companies, corresponding to 10 performance profile alternatives.

\subsubsection{Stage 4.2 - Defining accident risk categories and boundaries}

One of the most important stages in implementing Electre Tri consists in defining the categories and boundaries that demarcate them. In using the methodology one works with five Accident Risk Categories (A, B, C, D, and E) in a decreasing order of preference, as well as four boundaries. Each boundary represents values of standard performance in each group of desired requirement, which delimit two subsequent Categories. Each Category is associated to a classification (Very Low Risk, Low Risk, Moderate Risk, High Risk, and Very High Risk) that reflects the performance of the alternatives of profiles concerning services provided by companies working with road transportation of dangerous goods in light of the groups of desired requirements. Table 3 illustrates theses definitions and settings for the hypothetical example.

According to Roy (1985) and Mousseau \& Slowinski (1996), for each desired requirement gj considered, the parameters of limits of indifference (qj) and preference (pj) can be assimilated into the decision model. Table 4 presents parameter values established from the interpretation of the performance of alternatives (Table 2) and the values of standard performance of boundaries (Table 3).

In the hypothetical example, for illustration purposes, the following elements have been taken into consideration, in light of the criterion g5: value of the alternative a4, standard value of the boundary b3, and the limits of indifference and preference, represented by $\mathrm{g} 5(\mathrm{a} 4)=5, \mathrm{~g} 5(\mathrm{~b} 3)=1, \mathrm{q}=1$ and $\mathrm{p}=2$, correspondingly. Considering the relations mentioned and the corresponding values, it is possible to conclude that the alternative a4 is more desirable than the boundary b3 (a4 P5 b3) in light of the criterion g5. A similar procedure is performed for all the other criteria, alternatives and boundaries, using the Electre Tri software. Still according to Roy (1985) and Vincke (1989), for ascribing the alternative to one of the Accident Risk Categories the cutoff level $\lambda=0.76$ is considered, a value that ascribes an intermediate level of strictness to the analysis, since $\lambda \in[0.5 ; 1]$. After the data have been processed by the Electre Tri software, according to the guidelines presented in the manuals by Mousseau et al. $(2000 ; 2002)$, it is possible to verify the assignment of alternatives to the Risk Accident Categories, according to the hypothetical example shown in Table 5. At seen in Table 5, service alternatives of RTDG companies can be allocated on a pessimistic or optimistic scenario, according to the performance attributes in relation to the borders of Accident Risk Classes. 
Table 2: Hypothetical examples of performance of the services provided by RTDG companies according to desired requirements

\begin{tabular}{|c|c|c|c|c|c|c|c|c|c|c|c|}
\hline \multirow{2}{*}{$\begin{array}{l}\text { Desired } \\
\text { Requirements }\end{array}$} & \multirow{2}{*}{$\begin{array}{l}\text { Considered } \\
\text { Aspects }\end{array}$} & \multicolumn{5}{|c|}{ Performance Alternatives } & \multirow[b]{2}{*}{ a6 } & \multirow[b]{2}{*}{ a7 } & \multirow[b]{2}{*}{ a8 } & \multirow[b]{2}{*}{ a9 } & \multirow[b]{2}{*}{ a10 } \\
\hline & & a1 & $\mathrm{a} 2$ & a3 & $\mathrm{a} 4$ & a5 & & & & & \\
\hline \multirow{5}{*}{ RD1 } & RD1.1 & 1 & 1 & 1 & 1 & 1 & 1 & 1 & 0 & 1 & 0 \\
\hline & RD1.2 & 1 & 1 & 1 & 1 & 1 & 1 & 0 & 1 & 0 & 0 \\
\hline & RD1.3 & 1 & 1 & 1 & 0 & 0 & 0 & 0 & 1 & 0 & 0 \\
\hline & RD1.4 & 1 & 1 & 0 & 1 & 1 & 1 & 0 & 1 & 0 & 0 \\
\hline & RD1.5 & 1 & 0 & 0 & 0 & 0 & 1 & 1 & 1 & 0 & 0 \\
\hline \multirow[t]{3}{*}{ Total } & & 5 & 4 & 3 & 3 & 3 & 4 & 2 & 4 & 1 & 0 \\
\hline & RD2.1 & 1 & 1 & 1 & 1 & 1 & 0 & 1 & 1 & 1 & 1 \\
\hline & $\mathrm{RD} 2.2$ & 1 & 1 & 1 & 1 & 1 & 1 & 1 & 1 & 1 & 0 \\
\hline \multirow[t]{3}{*}{ RD2 } & RD2.3 & 1 & 1 & 0 & 0 & 1 & 0 & 0 & 0 & 0 & 0 \\
\hline & RD2.4 & 1 & 0 & 0 & 0 & 1 & 1 & 1 & 1 & 0 & 0 \\
\hline & RD2.5 & 0 & 0 & 0 & 0 & 0 & 1 & 1 & 0 & 0 & 0 \\
\hline \multirow[t]{3}{*}{ Total } & & 4 & 3 & 2 & 2 & 4 & 3 & 4 & 3 & 2 & 1 \\
\hline & RD3.1 & 1 & 1 & 1 & 1 & 1 & 0 & 0 & 1 & 1 & 1 \\
\hline & RD3.2 & 1 & 1 & 1 & 0 & 1 & 0 & 0 & 0 & 0 & 0 \\
\hline \multirow[t]{3}{*}{ RD3 } & RD3.3 & 1 & 1 & 0 & 0 & 0 & 1 & 1 & 0 & 0 & 0 \\
\hline & RD3.4 & 1 & 0 & 1 & 1 & 0 & 1 & 1 & 1 & 1 & 0 \\
\hline & RD3.5 & 0 & 0 & 0 & 0 & 0 & 1 & 1 & 1 & 0 & 0 \\
\hline \multirow[t]{3}{*}{ Total } & & 4 & 3 & 3 & 2 & 2 & 3 & 3 & 3 & 2 & 1 \\
\hline & RD4.1 & 1 & 1 & 1 & 1 & 1 & 0 & 0 & 1 & 1 & 0 \\
\hline & RD4.2 & 1 & 1 & 1 & 0 & 1 & 1 & 1 & 1 & 0 & 0 \\
\hline \multirow[t]{3}{*}{ RD4 } & RD4.3 & 1 & 1 & 0 & 1 & 1 & 1 & 1 & 1 & 0 & 0 \\
\hline & RD4.4 & 1 & 0 & 0 & 0 & 0 & 1 & 1 & 0 & 0 & 0 \\
\hline & RD4.5 & 0 & 0 & 0 & 0 & 0 & 1 & 1 & 1 & 1 & 0 \\
\hline \multirow[t]{3}{*}{ Total } & & 4 & 3 & 2 & 2 & 3 & 4 & 4 & 4 & 2 & 0 \\
\hline & RD4.1 & 1 & 1 & 1 & 1 & 1 & 0 & 1 & 1 & 0 & 1 \\
\hline & RD4.2 & 1 & 1 & 1 & 1 & 0 & 0 & 1 & 1 & 0 & 1 \\
\hline \multirow[t]{3}{*}{ RD5 } & RD4.3 & 1 & 1 & 1 & 1 & 1 & 0 & 1 & 0 & 1 & 0 \\
\hline & RD4.4 & 1 & 0 & 0 & 1 & 0 & 0 & 1 & 1 & 1 & 0 \\
\hline & RD4.5 & 0 & 0 & 0 & 1 & 1 & 0 & 0 & 1 & 0 & 0 \\
\hline Total & & 4 & 3 & 3 & 5 & 3 & 0 & 4 & 4 & 2 & 2 \\
\hline
\end{tabular}

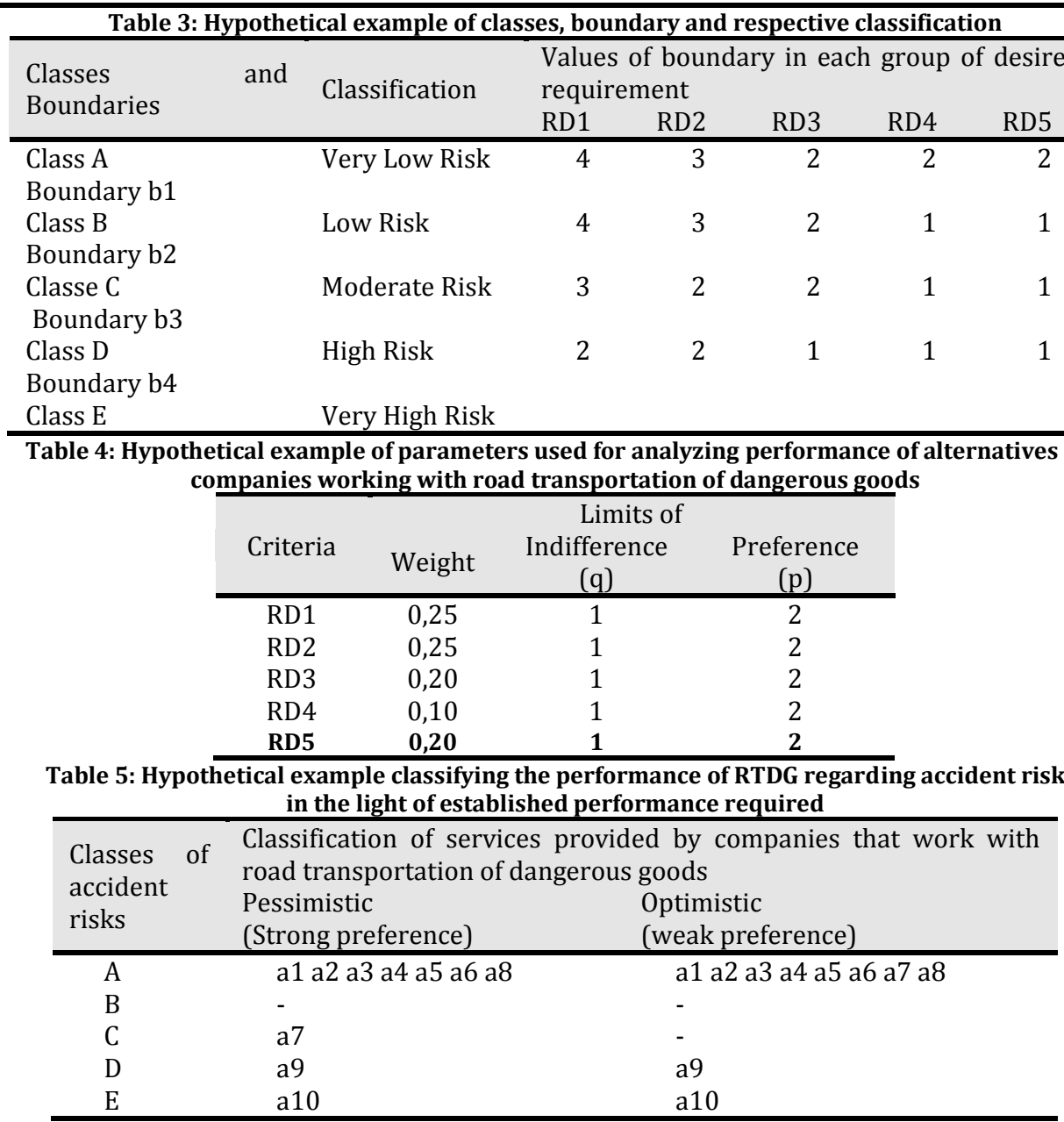




\section{Conclusion}

The present paper aimed at outlining a methodology for the identification and assessment of the desired requirements that RTDG companies must meet, so that the government can assess and classify the services such organizations provide when it comes to accident risks, based on the joint view of the main groups of actors.

The proposed methodology attempted to use important tools such as the identification and analysis of the key stakeholders; multicriterial decision support; multivariate data analysis; and classification of the performance profiles of services.

Applying the methodology proposed for a hypothetical example, resulted in the identification of the main actors; the listing of the main attributes desirable in categories; obtaining their weights; the list of services provided alternatives; defining the upper and lower limits of Accident Risk Classes; and the classification of the services provided to contracting in optimistic and pessimistic scenarios.

Among the advantages of the proposed methodology, it is possible to mention: it supports the establishment of a compliance program by the government; once an overview of the national status of companies working with road transportation of dangerous goods concerning Accident Risk Categories is known, the government can establish progressive performance goals for the companies that find themselves in lower performance Categories (Very High and/or High Risk); and it is possible to add a quantifier of desired requirements according to the needs of decision-makers.

Difficulties and limitations encountered at work: there was a theoretical application and a lack of access to real and direct data of the RTDG companies.

For future research, this paper suggests carrying out a comprehensive market study on road transportation of dangerous products, with a view to proposing a methodology in which the government can base the establishment of progressive performance goals for companies working with road transportation of dangerous goods that present a low performance level (High and Very High Risk).

\section{References}

ANTT (2015). National Agency for Land Transportation, Brasilia. Available in: www.antt.gov.br. Accessed at: May 2015.

Centrone, G. (2009). Modeling a Real Time Decision Support System for Hazmat Transportation in a Sustainable Oriented Motorway Environment (Doctoral dissertation). Università degli Studi di Trieste. Italia.

Corrar, L. J. et al. (2009). Multivariate Analysis for Management Courses, Accounting and Economics. Ed. Atlas. São Paulo, SP.

Fisichella, M., Targon, V., \& Pandolfi, A. (2009). The framework for dangerous goods tracking and management. The Integrated Information System. IEEE /International Conference on Computing and Communication Technologies - RIVF09. Da Nang, Vietnan.

GAPI (2002). Analysis Group Innovation Policies. Methodology for Public Policy Analysis. Unicamp. Campinas, SP.

Lieggio Júnior, M. (2012). Road Transportation of Dangerous Goods: Methodological Proposal for Evaluation and Classification of Services provided by the transportation companies regardind Accident Risks (Doctoral dissertation). University of Brasilia - UnB, Brasília, DF.

Lieggio Júnior, M., Granemann, S. R., \& Souza, O. A. (2012). Applicability of multicriteria analysis to decision problems in road transport of dangerous goods: a theoretical perspective. Journal of Transport Literature, Vol. 6(2), pp. 197-217.

Lieggio Júnior, M. (2008). Road Transportation of Dangerous Goods: Proposed Methodology for Choosing Transportation Companies to Focus on Risk Management (Master's thesis). Posgraduate Program in Transportation. University of Brasilia - UnB, Brasília, DF.

Meyers, J. (2005). Analysis of the Power of Participants. International Institute for Environment and Development. London, UK.

Mousseau, V., \& Slowinski, R. (1996). Inferring an ELECTRE TRI Model from Assignment Examples. LAMSADE. Université de ParisDauphine(140): 19.

PHMSA (2015). Pipeline and Hazardous Material Safety Administration. Available in: www.phmsa.dot.gov. Accessed at: April 2015.

Roy, B. (1985). Méthodologie Multicritère D'Aide à la Décision. Economica. Paris.

Russo, F., Vitetta, A., Rindone, C., Delfino, G., \& Quattrone, A. (2008). ITS for Monitoring and Estimating Road Accident Probability for Dangerous Goods Transport. European Transport Conference. Netherlands.

Tatham, A. et al. (2009). Multivariate Data Analysis. Bookman. Porto Alegre, RS.

UNECE (2013). Recommendation on the Transport of Dangerous Goods - Model Regulations. United Nations - UN, 18th rev. ed. New York and Geneva.

Vincke, P. (1982). Presentation et Analyse de Neuf Methodes Multicriteres Interactives. Laboratoire d'Analyse et Modélisation de Systemes pour l'Aide à La Decision - LAMSADE. Université de Paris-Dauphine.

Yu, W. (1992). ELECTRE TRI - Aspects Méthodologiques et manuel d'utilisation. LAMSADE. Université de Paris-Dauphine (74): 100.

\section{Resumo}

O objetivo deste artigo é propor uma metodologia para avaliar e classificar os serviços prestados pelas empresas de transporte rodoviário de produtos perigosos quanto a risco de acidentes durante as operações de transporte. A proposta metodológica encontra-se dividida em cinco etapas: reconhecimento da necessidade do estabelecimento de marco regulatório; identificação e análise dos principais autores; identificação dos principais requisitos desejáveis de uma empresa de transporte rodoviário de produtos perigosos; obtenção dos pesos dos requisitos desejáveis e dos aspectos considerados; e classificação dos serviços prestados. Um exemplo hipotético permitiu a classificação dos serviços prestados pelas empresas de transporte brasileiras desse tipo de produto nas classes de risco de acidentes..

Palavras-chave: transporte rodoviário de produtos perigosos, risco de acidentes, suporte à decisão multicritério, classificação de performance, electre tri 